\title{
ON THE \\ EFFICACY
}

OF THE

\section{BARK OF THE SWIETENIA FEBRIFUGA,}

\author{
AS A \\ SUBSTTTUTE FOR THAT OF THE CINCHONA, \\ By P. BRETON, EsQ. \\ assistant SURgen TO THE RHAMghUR BatTaLION, IN THE. \\ EAST INDIES. \\ COMMUNICATED BY \\ DR. ROGET. \\ Read March 14, 1820.
}

I FIRST became acquainted with the virtues of the bark of the swietenia febrifuga, in the month of August 1803, from the report of Dr. James Campbell, apothecary general, who obligingly presented me with $20 \mathrm{lbs}$. of it for trial. I found it so effectually to answer the purposes of cinchona, that I was induced to request a further supply, which Dr. Campbell, with his usual goodness, did me the favor to grant without hesitation. While in the province of Cuttuck, I made every search for the 
swietenia bark, but without success. On my arrival at Hazareebagh in 1805 , to assume the medical charge of the Rhamghur battalion, I expressed to lieut. Broughton, who then commanded the corps, and was well acquainted with the bark, my wish to search for it in the mountains, in the vicinity of our cantonments. I accordingly commenced my research, but notwithstanding all my exertions, labour and expense, I had not the good fortune to discover the tree on that occasion, nor had I any further opportunity of doing so, till the corps was employed on actual service in 1808, in a very wild and dreary country, on the borders of Singboom, bounded on all sides by immense chains of mountains.

In this country it was, that I was fortunate enough for the first time to discover the tree, but as I could only get information of the existence of a very few, (although a number of natives were employed to scour the jungles in quest of them,) I concluded that the plant was extremely scarce, and that I had no prospect of succeeding in the object of my wishes. I nevertheless persisted in my pursuit, till the return of the corps to cantonments, but still with no better success than before. At length, despairing of being ever able to meet with these trees in sufficient abundance, to answer any useful purpose, I abandoned my research altogether. 
On the corps being again ordered to take the field, in Dec. 1808, but in a different direction, I resolved to make another effort to accomplish the object of my wishes. It was not, however, till the month of June 1809, that my labours were amply rewarded by the discovering of a forest of these trees, in the vicinity of Omedurdah, at the distance of about twenty kos from the cantonment of Hazareebagh.

From the trees I discovered in 1808, I procured a sufficient quantity of the bark, to enable me to institute a series of experiments, and the success that has attended my labours and exertions, has exceeded my most sanguine expectations. In a number of cases of confirmed remittent bilious fevers, (commonly called jungle fever, I have put this bark to the fairest possible test ; and as success was uniformly the result of my repeated trials, I think I am warranted in concluding it to be an efficient substitute for the Peruvian bark. In common intermittent fevers, I have employed this bark very extensively, and with invariable success. I have also put this drug to the test of trial in three cases of gangrene and mortification, and in a case of suppurated liver; but as it was accompanied with auxiliaries, (such as laudanum and poultices of milk bread and keem leaves boiled together, ) I cannot speak so positively of its actual efficacy in these instances. The uniform result, however, of 
so many experiments satisfied my own mind, that the swietenia febrifuga answers every purpose of Peruvian bark, in allaying irritability, and restoring strength. In medicine, more than in any other branch of philosophy, it is extremely difficult to unfold, with precision, the causes which operate in producing alterations, either in healthy or morbid bodies, and I am well aware, that effects are often ascribed to medicine which belong exclusively to nature. But I trust I shall not be ac. cused of being visionary or enthusiastic, when I avow my own conviction, after having long employed this bark in every case where cinchona is indicated, that it forms a completely efficient substitute for the American drug, and that time alone is required to extend that general conviction of its efficacy, which every succeeding experiment will assuredly tend to impress.

If this bark shall be ultimately proved, (as I am almost certain it will,) equal in effect to the cinchona, the benefit that will result from it to Great Britain, and her vast dependencies in the East, especially in the present precarious state of our actual relations with America, will be incalculable.

Hazareebagh, June 4, 1811. 


\section{CASE I.}

One of the company's mahouts at this station, while employed in pursuit of the wild elephants that visited the cantonments of Hazareebagh, in October 1809, and were subsequently killed there, was attacked by one of those animals, and thrown to the ground with such violence, that his leg was badly fractured, about four or five inches above the ankle joint. Being myself at Shehur Ghantly at the time of the accident, I was of course precluded from rendering the man any assistance. The fracture, however, was reduced by my native doctors in the usual way; but on my return to Hazareebagh, I was much distressed at finding the poor man's foot actually mortifying, and his health declining fast. In this stage of his condition, amputation would have exposed his life to certain hazard, without any apparent prospect of success to counterbalance the risk. $\mathrm{My}$ attention was therefore exclusively directed to what is the last resource in similar cases, the causing a separation of the dead from the living part, by inducing a healthy action in his general system. I accordingly lost no time in commencing with the swietenia febrifuga, combined with opium, and persevered in its use without intermission, till a separation actually took place without the aid of the knife, the foot, including the processes forming the inner and outer ankle, having fallen off from the tibia 
and fibula by the mere vis medicatrix naturæ. In other words, nature performed the necessary operation on this limb, leaving to my further management a well-conditioned stump, which was afterwards so completely healed, as to admit of the man's walking about with the aid of a wooden substitute for his foot.

It is worthy of observation, that, in this case, mortification had actually commenced, and was making rapid progress when I first examined the fractured limb. The man's health was at the same time so much impaired, that he appeared to me to be sinking, when I began to exhibit the swietenia febrifuga.

From these plain and visible facts, combined with a consideration of the bad habit of body generally contracted by people of this description, from their debauched mode of living, it appears reasonable to infer, that if the man had been left entirely to nature, he would have lost his life ; and that his cure, therefore, may very fairly be ascribed to the virtue of the bark of the swietenia febrifuga.

\section{CASE' 11 .}

In the month of October 1810, a hackery driver at the station of Chiltra, in a state of extreme in. toxication, fell from his hackery, and by some voL. XI. 
means or other so lacerated his scrotum as to cause a protrusion of one of the testes. In this state the unfortunate man must have lain several hours; for it was reported that the accident happened in the morning, and it was not until ten at night that he was brought to the house of $\mathrm{Mr}$. W. Louther, the then acting register of Ramghur. Being at the time in medical attendance at $\mathrm{Mr}$. Louther's, I was requested to see the man.

On examining the part injured, I found the inferior portion of the scrotum considerably lacerated, and the testis which protruded through it so much swollen and discoloured, as to render its reduction wholly impracticable. No other alternative appearing to me than that of removing the testis, I accordingly determined at once to perform castration. The operation was performed in the usual way in the presence of Mr. Louther, and for two days every appearance was favourable. On the third day after the operation, however, I was distressed at observing considerable inflammation, and appearances of incipient gangrene and mortification. The man's health seemed much affected, his pulse became very quick, and in the course of the day symptoms of irritation began to manifest themselves. On observing this unfavourable change, I began to administer opium and the swietenia febrifuga every hour, in as large quantities as the stomach would bear. Poultices of bread and milk and keem leaves mixed together were applied 
morning and evening, and every other attention paid that the case seemed to require. After persevering in this course for two days, I had the gratification to see evident marks of healthy action in the part, and a disposition to separation of the dead from the living part. The same course of remedies, however, was persisted in till my mind was relieved of all apprehensions of danger, when they were omitted, and the wound treated as a common ulcer. At the expiration of about three weeks from the day on which the accident happened, this poor fellow recovered sufficiently to admit of his returning to Patna.

When the age of this man is considered, (which I think must have exceeded sixty, the extreme intoxication he was in nearly a whole day, (for he had not recovered from it when he was brought to Mr. Louther's bungalow, and the symptoms that ensued subsequently to the operation, I am induced to allow the swietenia febrifuga its full share in preserving the life of this unfortunate man.

\section{CASE III.}

In the month of March 1811, a Sepoy was admitted into the hospital for a venereal complaint. Mercury was administered, and his case treated in the usual manner. For the space of nearly a 
month, his venereal symptoms seemed to yield gradually to the influence of mercury; when on a sudden, and without any apparent cause, his bubo (which was very nearly healed) broke out and enlarged considerably, and a dark-coloured slough covered its whole surface. His health was materially affected, his reşpiration accelerated, his pulse very quick, and symptoms of irritation were manifest. Conceiving that I had no time to lose, I immediately commenced exhibiting the swietenia febrifuga and opium every hour, and applied poul. tices of bread and milk and keem leaves mixed together. In the course of about 24 hours, I observed an evident change for the better, but continued the use of these remedies till all danger was removed, when I substituted the decoction of the woods and nitric acid. The man is now nearly well, and in all probability will be able to return to his duty in a few days more.

From these three cases, I am induced to place some confidence in the virtue of the swietenia febrifuga ; for I doubt whether poultices and opium alone would have sufficed in effecting a cure.

Hazareebagh, June 4th, 1811.

On the 15th June 1811, I was requested to see a dooreeah, or dog-keeper, of Lieutenant Jackson, who was supposed to be ill of a fever. 
On examining the man, I found that his complaint was a severe affection of liver, which appeared considerably enlarged and indurated.

Judging from the appearance of the tumefaction in the right epigastric region, and from his symptoms, (which were fever, great pain in his right side increasing considerably by pressure, a hectic kind of cough, difficult respiration, quick and irritable pulse, great debility, and occasional shudderings and tremors,) that matter had already begun to form in the liver, I conceived it adviseable to endeavour to promote laudable suppuration, rather than attempt to effect a cure by means of resolution. With this view, therefore, after clearing the primæ viæ, I commenced exhibiting the bark of the swietenia febrifuga in substance, in quantities of about half an ounce to six drachms in the course of four and twenty hours, combined with small doses of tincture of opium. This quantity I employed without intermission for ten days, during which poultices of keem leaves were applied on the external tumor morning and evening regularly, with the view of softening the integuments, and assisting in some degree in the suppurative process.

On the 23d of the month, I perceived that the tumor (which was before extremely hard and painful to the slightest touch) had become soft and pulpy. 
On the 25th, a fluctuation in the tumor being evident, I lost no time in opening it. The moment the incision was made, an immense quantity of matter escaped, and continued to flow gradually the whole of the day. The former quantity of the swietenia bark was immediately increased to ziss in the 24 hours, and a few drops of laudanum united with each dose of the bark, every other attention being paid that the case seemed to require. The great relief which the poor man experienced from these remedies induced me to persist in their use, till all appearance of danger had ceased, without the aid of any other medicine than occasional laxatives.

A case so decisive as this would appear calculated to remove any doubt that may have been hitherto entertained of the virtues of this bark, since it has obviously performed, in this remarkable instance, precisely the same office which the Peruvian bark would have done had the latter been administered ; and as the man has actually recovered from this formidable disease, it may be fairly inferred that his cure was promoted and accelerated by the good effects of the bark of the swietenia febrifuga, in removing irritability, and inducing healthy action. 
Extract of a Letter from Mr. P. Cochrane, Assistant Surgeon, dated Meerut, 30th January, 1812.

" I believe I can say, that I have seen the swietenia febrifuga more extensively used than any other surgeon in the country. About the year 1797, when I had charge of the hospitals at Futtyghur, Mr. Kennedy, who was an enthusiast in its favour, was doing duty under me. I got up whole wine-chests full of the bark from Chunarghur; and through Mr. Kennedy's zeal, and my encouragement, all the other surgeons attending the hospitals adopted its use, which was continued more or less till I joined the grand army in 1803.

" Hundreds of cases in which it was prescribed were recorded in the hospital diaries, of which, I am sorry to say, sufficient care was not taken to preserve them. We thought it (all but Kennedy) inferior to good bark; but I can honestly, and from much actual observation, add my testimóny to its general utility in most cases where the cinchona would have been thought the best remedy. We thought (from an analysis made of it by the celebrated Dr. Irving) that its quality of astringency predominated, and we, therefore, occasionally combined it with aromatics and bitters."' 
Extract of a Letter from J. Robinson, Esq. Assistant Surgeon of the Civil Station of Benares, dated Benares, January 12, 1812.

"I have been in the habit of using this drug, (the swietenia febrifuga,) both in powder and extract, ever since I came to Benares, largely amongst the poorer natives, and am perfectly convinced of its equal efficacy with the cinchona."

Mr. M. Cheese, garrison surgeon at Fort William, says, in a letter to Mr. Breton: "I have given the swietenia febrifuga ever since you were kind enough to favour me with it; and think it preferable to any bark we have now in Calcutta, although I have not had sufficient time to judge of its qualities."

Extract of a Letter from J. M. Davidson, Esq. Surgeon of the Civil Station of Purneah, dated Purneah, June 23, 1817.

"I was not quite ignorant of the medicine before receiving your remarks; but these, with the testimony of your correspondents, men of celebrity and experience, has fully confirmed the favourable impression of the utility of this medicine, which 
previous exhibition of it had given me. While surgeon of Burdavaun, on a particular occasion of great prevalence of fever, having expended my usual supply of bark, at the suggestion of my friend Mr. Fleming, then judge of the district, I had recourse to the rohun bark *, of which he gave me a supply, with perfect success. The fever was a remittent, \&c. After evacuations, I gave the bark in substance and decoction; during the remission. I could observe no difference in its effects from the Peruvian bark; but it occurred to me in some cases, that it appeared to be retained in the stomach in substance in greater quantities than the bark (cinchona) would have been, probably from the presence of an aromatic principle."

In a letter of a subsequent date, (July 19, 1817 ,) the same gentleman says, "I have used no Peruvian bark since your kind supply of the rohun came to hand. Its effects are exactly what I could have expected from the Peruvian bark in cases of fevers, remittent and intermittent; and when employed as a tonic in cases of suppuration and debility. I consider that you have conferred an important service on the profession and the community by the introduction of this valuable medicine."

- Rohun is the native name for the swietenia febrifuga. 
Extract of a Letter from Dr. Roxburgh, dated Botanic Garden, 29th July, 1811.

"I return you many thanks for the perusal of the enclosed cases of gangrene and suppuration of the liver. They are fully as much to the point as can possibly be, and correspond very well with the success. I had with this bark about twenty years ago, when I first discovered the tree, and its virtues. The late Mr. Kennedy, of this medical establishment, chanced to be in Samulcotah, where I then was stationed, and got from me a quantity of the bark, which he brought to Bengal, and used with complete success. He was, I believe, the first person who found the tree in this quarter; and also, I believe, he continued to use the bark in his practice to the time of his death."

In another letter, Dr. Roxburgh says, "I presume the best season for collecting the swietenia bark will be, when the sap begins to ascend freely, at which period the bark separates readily. I believe the bark of the small, or rather middling-sized branches, the best for medical purposes, and you may use it as soon as it is sufficiently dry for powdering." In a subsequent letter, dated July 3, 1811, he mentions the swietenia as having been tried at Batavia, and found highly useful in the fevers of that place. 
Extract of a Letter from John Grant, Esq. Assistant Surgeon to the 4th Native Regiment, dated from the Camp at Sumbhulpoor, June 28, 1818.

"I now daily use the powder of swietenia febrifuga in remittent and quotidian intermittent fevers; and, as far as I can judge, it answers every purpose of Peruvian bark. I am not yet sufficiently acquainted with swietenia to determine positively on its effects; but I declare, upon my honour, that I am strongly inclined to think it sits easier on the stomach, and produces less irritation than cinchona. That cinchona, in this country especially, does frequently produce purging, tormina, and even a trifling degree of vertigo, and febrile irritation, I am perfectly convinced of from experience. This may arise from idiosyncrasy, or some change in the component parts of cinchona consequent upon age, decay, damage on the voyage, laying long in store, \&c.; and now having a medicine, perfectly at hand, equal to the cinchona, is a great desideratum to this country, situated, as you observe, so far distant from Peru, and subject by some future political change to be deprived of the article altogether."

Having observed in the Edinburgh Dispensatory, that the extract of the bark of the swietenia febrifuga, which Dr. Roxburgh sent home several years 
ago, was not distinguished from the kino of the shops, I have lately been endeavouring to ascertain the nature and degree of their approximation to each other in their respective properties : but the experiments $I$ have recently made with this extract and gum kino, according to Dr. Fothergill's method, have led me to conclude that there is a considerable difference between them. I observe, that the extract of the bark of the swietenia febrifuga is intensely bitter, while the kino, on the contrary, possesses no bitterness whatever. The former is obviously less astringent than the latter; and the precipitate formed by the union of a solution of it with sulphate of iron does not seem disposed to concrete in the same manner as the precipitate of gum kino. The extract, when dried and powdered, is not of that brick-dust colour which kino assumes on being pulverized; neither does it give the same deep red tincture to spirits. It is also by no means so friable, nor of the same gummy nature as the African drug. These several circumstances combined, would naturally suggest the probability of a verbal inadvertency in the Edinburgh Dispensatory, and that the extract from the wood of the swietenia febrifuga is that which is meant, as being analagous to gum kino, instead of the extract of the bark of that tree.

Dr. Roxburgh states, that the coloured part of the wood of the swietenia febrifuga seems as fit to yield catechu as the mimosa catechu itself. I have 
recently prepared extracts from the wood of both these trees, in the same manner as the natives are described by Mr. Ker to make catechu in this district; and on comparing them with each other, I find that there a striking difference between them. This extract from the swietenia febrifuga is unquestionably more astringent than catechu; and, both in its appearance and actual properties, appears so closely allied to gum kino, that I am fully disposed to believe, it may at all times be substituted for the latter. Now Dr. Lewis observes, that catechu comes nearer to gum kino than any other vegetable substance we are acquainted with, but that it is manifestly less astringent and somewhat different in other respects. It being therefore admitted, that there actually is some analogy between gum kino and catechu; and it being evident, that the extract from the wood of the swietenia febrifuga, while confessedly bearing some analogy to catechu, has a still greater resemblance to gum kino than the catechu itself has, we have strong grounds to presume that this extract may justly be identified with gum kino. Although this gum is supposed to exude from incisions made in the trunk of certain trees growing in the interior of Africa, it is still not at all improbable that the preparation of it by the natives there may be similar to that of catechu in this country. It will be seen, by the specimens I have sent to England, that the extract from the rood of 
the swietenia febrifuga and the gum kino bear a closer affinity to each other in every particular than either of them does to catechu, while the extract from the bark of the tree differs widely from the whole three. The extract from the wood of the swietenia tree glows on a red-hot iron like gum kino, without evincing any tendency to melt. Spirit of wine takes up about an equal quantity of this extract and of kino, and in every other particular also these two substances seem to correspond. If the further investigations of abler men shall establish the fact here presumed, that this extract is identically the gum kino, or at least a species of it, we shall no longer be dependent on Africa for this valuable drug.

In several instances of obstinate diarrhœa, and of disorders arising from laxity, I have employed this extract with great advantage; but my experience of its virtues is yet too limited to admit of my offering any confident opinion on the subject.

Bengal catechu, according to the analysis of Professor Davy, gave, in 200 grains, tannin 97 grains, peculiar extractive matter 73 grains, mucilage 16 grains, residual matter, sand with a small quantity of calcareous and aluminous earths, 14 grains. Now if gum kino and the extract from the wood of the swietenia febrifuga were analyzed in a similar way, we should be accurately informed of 
the degree of approximation of these three substances with each other, in their chemical combinations and physical properties.

\section{P. BRETON.}

The above documents were transmitled to the Society through the hands of Messrs. W. and T. Raikes and Co., of No. 79, London Wall, to whom they had been sent by Mr. Breton, together with specimens of the swietenia febrifuga, in quill, powder, and extract; and also of the bark of the pomegranate tree, the effects of which, as an anthelmintic in tænia, form the subject of the preceding paper. 